\title{
Chinese Vocational College English Teachers and Majors' Perceptions of the Product Approach and Process Approach and Attitudes toward the Application of the Product Process Approach
}

\author{
Zhenzhen Hu, Zhenzhen Wang \\ School of Foreign Languages, Chengdu Textile College, Chengdu, China \\ Email: 1025306676@qq.com
}

How to cite this paper: Hu, Z. Z., \& Wang, Z. Z. (2019). Chinese Vocational College English Teachers and Majors' Perceptions of the Product Approach and Process Approach and Attitudes toward the Application of the Product Process Approach. Creative Education, 10, 2400-2427. https://doi.org/10.4236/ce.2019.1011171

Received: September 17, 2019

Accepted: November 11, 2019

Published: November 14, 2019

Copyright $\odot 2019$ by author(s) and Scientific Research Publishing Inc. This work is licensed under the Creative Commons Attribution International License (CC BY 4.0).

http://creativecommons.org/licenses/by/4.0/

(c) (i) Open Access

\begin{abstract}
In this particular small-scale survey, questionnaires were sent to 50 students majoring in English and interviews with 4 teachers teaching English writing in vocational colleges were used to collect data. It is agreed that the traditional Product Approach to some extent was still useful due to learners' insufficiency in English competency and the exam-oriented approach of the Chinese education system. However, the product-oriented pedagogy is argued to overlook learners' creative thinking, problem-solving skills and the concept of the writing purpose and audience. Thus, the Process Approach is considered to be a much more sophisticated approach. Although the process writing has various advantages, it originated from L1 (English as a first language), which may not be wholly suitable to in an EFL (English as a foreign language) context. Hence, the adaptability and simplification of the original Process Approach are perceived to be significant. In addition, the main findings of the study indicated that both Chinese English teachers and majors held positive attitudes towards the Product Process Approach. They pointed out the synthesis might not only guarantee proper language input, but also enhance learners' communication skills and strengthen their understanding of the multiple drafts, the writing purpose and the audience. It is suggested that the synthesis might be useful if the two approaches are properly balanced according to different students' levels and various genres. The limitation of this study was the small sample that could not represent all the Chinese university teachers and students' views. In addition, it needs long-term empirical studies to further examine the validity and reliability of the synthesis.
\end{abstract}

\section{Keywords}

The Product Approach, The Process Approach, The Product Process Approach 


\section{Introduction}

Traditionally, Chinese English teachers tend to use the Product Approach to offer sufficient language input (Liu, 1999). This might help students survive the exams such as College English Test Band 4 (CET-4) thanks to the models and pre-exam practice. However, the traditional Product Approach encounters problems when English writing is meant to create a more meaningful written piece from a communicative perspective.

In January 2004 the Chinese Ministry of Education (You, 2004) put forward new requirements for college English teaching and learning. In recent years, a number of Chinese researchers and teachers (Miao et al., 2006; Yang \& Gao, 2013) have been influenced by the Process Approach in writing pedagogy from North America. With consideration to the adaptability of a western writing approach referring to the process writing pedagogy, Muncie (2002) pointed out that EFL writing instruction should leave proper space for grammar teaching, which is perceived to be a primary factor in enhancing EFL learners' writing competencies. It seems that traditional product-oriented classes should not be totally denied as they can enhance EFL learners' language input.

Here, in aiming to compensate for the traditional English writing instruction, the process writing strategy has its advantages. However, Chinese teachers may also need to consider the local culture and education system in order to achieve their teaching goals and guarantee the learner's foundation of English language (You, 2004). Thus, careful adaptation of the Process Approach seems important for EFL writing teachers (Caudery, 1995).

In the context of Chinese EFL learning environments, particular in English major classes, studies of the integration of the synthesis methodology: the Product Process Approach might be helpful to improve the teaching and learning of English writing. It is argued that Chinese English majors have the conditions such as smaller class sizes, greater familiarity with English, and individual tutors who could provide one to one guidance on their writing to facilitate the method's integration. Thus, here is the hypothesis that in their writing class the Product Process Approach has the possibility of being put into practice. In this paper, I aim to firstly understand Chinese English majors' and teachers' perceptions of the Product Approach and the Process Approach and secondly their attitudes towards the synthesis: the Product Process Approach.

\section{Literature Review}

\subsection{The Process Approach}

\subsubsection{Definition}

The Process Approach in an English writing instruction class may have different definitions in different contexts. For a general class, it could be broadly defined as a writing process consisting of several periods that are prewriting, drafting, revising and editing (Tribble, 1996; Hedge, 2005; Williams, 2005; Harmer, 2007). Here, to be more specific, a significant study by White and Arndt (1991) argues 
that the Process Approach could be divided into various detailed composing stages in order to create a final piece, namely generating, focusing, framing, drafting, evaluating and reviewing.

\subsubsection{Theoretical Foundation}

An important theory was proposed by Flower and Hayes (1981). There were three interactive elements in Flower-Hayes cognitive process strategy, namely, the outside environment of writing tasks, the long-term memory, and the production process itself.

According to Flower and Hayes's cognitive process theory, it may be easier for learners to find that the nature of writing itself is discovering ways to solve problems. In this way, writers could generate ideas and thoughts and translate them into written pieces.

\subsubsection{Advantages and Disadvantages of the Process Approach}

The advantages of the Process Approach might be generalized into three aspects:

First of all, it is a student-centered mode classroom (Tribble, 1996). That is to say, teachers may change the traditional role in terms of the authoritative person (Williams, 2005).

Secondly, students may better understand the writing process by participating in the process-based writing class (Brown, 1994; Yu \& Lee, 2015). Novice writers tend to regard the first draft as the final product without much creative thinking or understanding of revising. Thus, students are unable to improve their writing skills and thoroughly understand how to accomplish a good written piece (Susser, 1994). Thirdly, the Process Approach acknowledges writing as an interactive, communicative and collaborative activity (Hedge, 2005). The final production could be more effective in communication if students have a sense of their audience as well as achieving the writing purpose (Tribble, 1996; Scrivener, 2005). In addition, learners may benefit when revise their drafts based on the suggested comments from teacher and peer feedback and they can be encouraged and motivated by the teacher praise (Hedge, 2005).

However, the Process Approach has its limitations. firstly, it tends to take a large amount of time in going through a range of overlapping writing sections such as drafting, revising, and planning (Harmer, 2007). Then, when a writer carefully outlines the details of the draft, it may influence the spontaneous improvisation ability (Harmer, 2007). Moreover, it overlooks the language knowledge input part (Badger \& White, 2000), which could cause difficulties such as lack of lexis or unfamiliarity with the writing conventions to unskilled writers.

\subsection{The Product Approach}

\subsubsection{Definition}

The Product Approach is a traditional teaching method. Pincas (1982) defined "In this approach, learning to write has four stages: familiarization; controlled writing; guided writing; and free writing" (p. 22). At the beginning, teachers would 
present several writing models. Thus, learners could have intimate knowledge of the features and rhetorical devices of certain given writing models. Then, learners could freely practice and imitate the style and sentence structures.

\subsubsection{Theory Foundation}

Krashen's Input Hypothesis (1985) is the theoretical stance of the Product Approach. Krashen suggests the Comprehensible Input Hypothesis theory which includes five related hypotheses, namely, input, language acquisition, monitor, natural order and output. Krashen argues that a certain amount of language input could bring influential result in corresponding output referring to learners' compositions.

\subsubsection{Advantages and Disadvantages of the Product Approach}

The strengths of the Product Approach could be summarized into several aspects. Firstly, learners may gain sufficient language input referring to grammar instruction, vocabulary, sentence patterns, and rhetorical devices (Badger \& White, 2000). Secondly, to some extent, it is helpful for students to pass exams as they remember various models and pre-exam practice (Watson, 1982). In the Chinese exam-oriented education system, students need to pass various governmental exams to obtain diplomas.

The negative aspects of the Product Approach are that students often regard the first draft as the final piece without any modification required (Harmer, 2007). Furthermore, the Product Approach places too much emphasis on the correct use of the language (Badger \& White, 2000). It seems that learners in the product-based class may lack independent creative thinking and problem-solving skills (Badger \& White, 2000). In addition, it is a teacher-centered class (Nunan, 2001). Thus, students receive the knowledge passively and may not be provided with enough opportunities to communicate their ideas in class.

\subsection{Previous Studies}

The Process Approach has been applied and studied in L1, ESL and EFL context. It is argued that the Process Approach may be more efficient than the traditional Product Approach based on their research (Winer, 1992; Susser, 1994; Tribble, 1996; Badger \& White, 2000; Chen, 2005; Rao, 2007). However, the Product Approach is still likely to occupy a position of prestige (Watson, 1982; Muncie, 2002; Luo \& Li, 2003) in ESL and EFL education circles. This may be because English is not students' first language and adequate target language input is thought to be significant. Here, in order to enhance learners' writing ability, this again seems to suggest the importance of examining the effectiveness and limitations of the two writing approaches.

An earlier study by Flower and Hayes (1981) on the cognitive process theory of writing, noted that during the composing process, the writer needed to use their long-term memory for their repertoire of language knowledge and background information of a specific writing topic. Watson (1982) suggested a syn- 
thesis: the Product Process Approach into writing instruction. Watson noted that on one hand it was significant for learners to obtain language knowledge and imitate the native good vocabulary as well as sentence structures. On the other hand, the process-oriented approach could enhance learners' writing ability, problem-solving skills as well as communicative skills when learners wrote with the consideration of the writing purpose and potential audience. In addition, a study carried out by Kamimura (2000), of 35 Japanese EFL college students involved in a controlled writing experiment suggested that both the Product Approach and the Process Approach were significant writing instruction methods for EFL learners. Careful balance between the two approaches according to learners' different language competencies and various studying needs was also important. Furthermore, Wu (2010) investigated the effectiveness of the combining of the product method and the process method in Chinese universities. The findings indicated that writing teachers needed to balance the two approaches accordance to distinctive writing tasks or genres. For example, when teaching English majors how to compose their dissertations, teachers may need to use the Process Approach more than the product-oriented method. Moreover, a study including 60 Chinese university students by Chen (2005) showed that the product-based method and the process-based method were complementary teaching instruction and suggested that the Product Approach was much more suitable for less skilful writers while the Process Approach was proper for skilled writers. Moreover, according to Yang and Gao (2013), all the interviewed teachers in their study discerned that they took a mixture approach. In other words, they combined both product and process pedagogies' elements into their writing classes. It means that teachers begin with language input such as formulaic patterns and then explicit explanation of writing process like prewriting, drafting, revising, editing. Therefore, teachers stand in the middle point between product-oriented and process-based approach in order to better satisfy EFL learners' learning needs.

It seems that there is not much research on the validity of the combination of the product method and the process method and no study examined teachers and students' attitudes towards the combination. The aim of this paper is to understand Chinese English teachers and majors' views of these two approaches and their attitudes towards the synthesis: the Product Process Approach by using questionnaire and interview as the research methods.

\section{Methodology}

In this chapter, methods, sample selection, procedures used for data collection and analysis, and limitations of this research process will be described and justified at length. In this study, I aimed to gather and obtain Chinese teachers' and learners' various opinions on the issues including the perceptions of the Process Approach and their attitudes toward the application of the Product Process Approach into the writing course. Here I present the four research questions: 
1) What do Chinese English teachers and majors think of the traditional Product Approach?

2) To what extent do teachers and students understand the Process Approach?

3) To what extent do teachers apply and students experience the Process Approach?

4) What do teachers and students think of the Product Process Approach? Is it practical in current writing instruction?

\subsection{Instrumentation}

The purpose of mixed method is to achieve a complete picture of a target phenomenon from both quantitative and qualitative paradigms (Stringer, 2014). Compared with other methods and tools like observation, questionnaires and interviews will be used in combination and are considered as effective and feasible methods (Bell, 2005). For this particular small-scale study, the questionnaire and interview were chosen as the research methods. Considering the quantitative part, the self-completed questionnaire (see Appendix A) is a useful and convenient method to obtain students' views on product and process approaches based on their experiences with standardized questions.

However, the survey is unlikely to obtain an elaborative and in-depth understanding of their opinions towards the product and process pedagogies and the application of the Process Approach, therefore the followed-up semi-structured interview has been employed. Cohen, Manion and Morrison (2007) suggest: "The interview is a flexible tool for data collection, enabling multi-sensory channels to be used: verbal, non-verbal, spoken and heard" (p. 349). The negative aspects of interviews as a research technique are that it is time-consuming and has a danger in expressing biased opinions (Bell, 2005) which may cause trouble in reliability (Cohen, Manion, \& Morrison, 2007). However, the interview could "put flesh on the bones of the questionnaire responses" (p. 157) despite its limitations.

\subsection{Sample}

The sample size as well as the representativeness of the respondents is main issues in selection of the research sample (Bell, 2005). There are two types of sample in this research. The first sample was investigated by questionnaire. The sample individuals were 50 students who have been majored in English. They have experienced a more sophisticated instruction (exclusive textbooks, smaller class sizes and individual English tutors) in terms of English writing than other non-English majors. Hence, they may be more familiar with and have more insightful comments on writing issues. In addition, Chinese English majors are all required to take exams like the test for English majors (TEM4) which entails operational command of the English language, so they are more suited than other bilinguals in answering the questionnaire concerning English writing. Subjects were recruited through emails, telephone, MSN, and personal networks. 
The second sample was studied by interview. The sample individuals consisted of four English major teachers. Two of them are young English teachers who both teach English and non-English majors and they have at least 5 years English writing teaching experience. Besides, the other two are very experienced English major teachers who have more than 8 years teaching experience. Thus they are familiar with the writing instruction methodology. Each of them has substantial knowledge of various writing approaches such as the Product Approach and the Process Approach. Moreover, they are willing to support this study with their teaching experiences and share insights in terms of English writing instruction.

\subsection{Data Collection and Analysis}

The design of the questions in the interview was based on the four research questions mentioned at the beginning of this chapter. In addition, most of the questions in the questionnaire were also designed according to the four research questions and a few from other studies (Caudery, 1995). I designed the questionnaire using an online survey tool (Wenjuanxing) and distributed it by email and online chatting tools attached with the link and student consent form. There were various question types, for example, scaled responses question 7 (see Appendix A). I interviewed the teachers through APP Wechat. The plan was to collect 80 questionnaire replies and interview 10 teachers. The result turned out to be just 50 replies (62.5\% reply rate from students) and only four college teachers were available for the interviews because they were busy with final exams during that period.

For the interviews, first of all, I recorded and transcribed the conversations (see Appendix C, a transcript of one of the interviews). Secondly, the transcripts were categorized into several classifications: for example, I put teachers into two groups-those who use the Process Approach and those who do not. For the questionnaire, it was necessary to make good preparation and description on the raw data (Munn \& Drever, 2004). With the aim to make the materials manageable and easy to analyze, I labeled closed questions based on question types such as labeled the multiple choice question $\mathrm{M}$, yes or no question $\mathrm{Y} / \mathrm{N}$. There was only one open-ended question (which teaching mode of writing do you prefer, please write down the main reasons briefly). In this question were three items namely the Product Approach, the Process Approach and the Product Process Approach. I divided their choice into three categories and analyzed their comments. In addition, according to the four research questions, I categorized all the questions into four parts. Then, I reported them in detail and I also pointed out a few unexpected responses.

\subsection{Limitations}

Here were the limitations. Firstly, the number of questionnaire replies did not reach the anticipated amount. What's more, teachers were not available for in- 
terviews due to their workloads. In further research, I will need to schedule carefully and ensure participants' free time in advance. Finally, there is a need for long-term empirical studies to further examine the feasibility of the Product Process Approach.

\section{Findings}

This chapter presents the important as well as unexpected data from the survey and tries to answer the four research questions according to the findings. The participants in the questionnaire were made up of 24 college students and 26 graduates and 4 English teachers' opinions were investigated by the interview.

\subsection{Research Question 1: What Do Chinese English Teachers and Majors Think of the Traditional Product Approach?}

The first research question is to find out Chinese English teachers and majors views of the traditional Product Approach based on their teaching and learning experiences. The product-oriented pedagogy may still dominate an important position in the EFL context (Nunan, 2001) like China (Liu, 1999). In addition, both Chinese university teachers and students think the Product Approach, to some extent, is useful to pass governmental higher education exams such as CET-4 (You, 2004).

This was a scaled responses question 8 in the questionnaire (see Appendix A). Figure 1 shows that $16 \%$ of respondents strongly agreed writing models are useful, the majority of them (60\%) agreed, $20 \%$ of them neither agreed nor disagreed, and only $4 \%$ of them disagreed. Obviously, there were no respondents who strongly disagreed. It could be seen that most of the participants thought the writing models to some degree were helpful in improving their writing proficiency.

Table 1 depicts students' different opinions about the traditional Product Approach. Question 3 (see Appendix A) allowed students to choose more than one item. It can be seen that many of the participants were aware of the Product Approach's advantages, most of them choosing item A C and E. On the contrary,

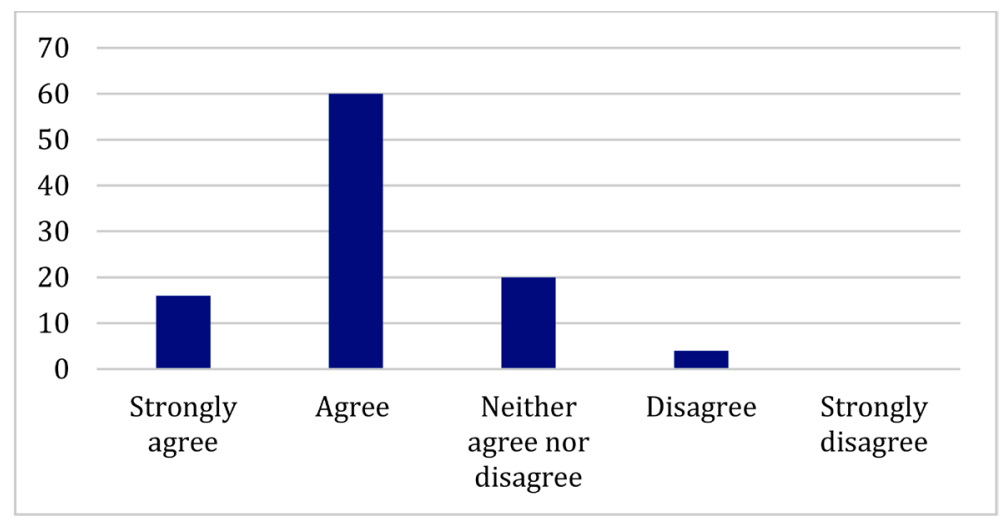

Figure 1. Do you think writing models (e.g. text-books and models provided by teachers) are useful? $(\mathrm{n}=50)$. 
Table 1. Learners views towards the product approach $(n=50)$.

\begin{tabular}{cccc}
\hline & Statements & Number & Percent \\
\hline A & It is helpful to provide writing models for students to imitate. & 25 & $50 \%$ \\
B & It only focuses on the final piece without revisions. & 12 & $24 \%$ \\
C & It helps to learn various good sentence patterns. & 25 & $50 \%$ \\
D & It lacks the concept of audience. & 11 & $22 \%$ \\
E & It helps to survive the exam. & 30 & $60 \%$ \\
F & It lacks creative thinking. & 32 & $64 \%$ \\
G & Others, please specify. & 2 & $4 \%$ \\
\hline
\end{tabular}

the participants' understanding of the disadvantages (item B and D) of this approach was more limited. The only exception was item $\mathrm{F}$ chosen by $64 \%$ of participants, which is surprising considering the fact that the Product Approach mainly focuses on imitating samples.

After showing the findings of the student participants' opinions towards the Product Approach, the teachers' data is presented. In the interview, when teachers were asked question 2 (see Appendix B): what do you think of the traditional Product Approach in writing class? Teachers all pointed out the positive as well as the negative sides of the Product Approach. In light of the disadvantages, teacher A and B commented:

"It is focusing on the exam, But... too fixed style in mind, lack flexibility." (teacher A) "The disadvantages, it only focuses on the final product, and sometimes lacks the concept or ideas of the audience and students cannot develop creative thinking." (teacher $B$ )

Teacher C said the Product Approach is "too boring". Teacher D felt a little bit upset as she mentioned after "giving students some sentence patterns", when she evaluated students' homework “...the result is the students' compositions look similar".

In terms of the advantages, teachers stated,

"The advantages... first of all it is helpful to provide model writings for students to imitate... secondly it helps to learn various good sentence patterns. And it helps to survive the exam." (teacher B)

"It is easy to use with large classes and easier to grade." (teacher D)

\subsection{Research Question 2: To What Extent Do Teachers and Students Understand the Process Approach?}

The aim of the second research question was to investigate whether English teachers and majors know about the Process Approach. It also aimed to study teachers' own definition as well as concept of the Process Approach. Firstly, the students' data would be presented as show below.

Figure 2 illustrates that $76 \%$ of the student respondents $(n=38)$ knew the Process Approach that occupied a large slice of the pie. It can be seen that the 


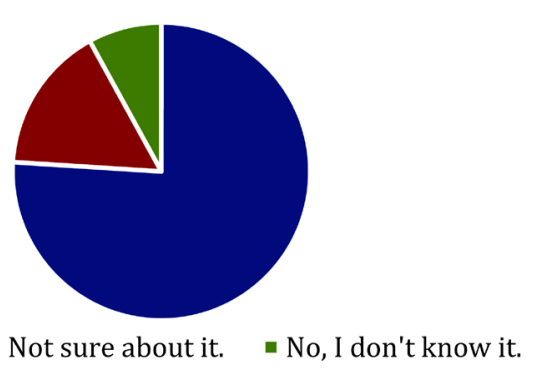

Figure 2. Do you know the Process Approach?

majority of the participants knew the Process Approach in contrast with only 4 students who did not know.

Secondly, considering the teacher interview part, question 3 (see Appendix B) asked tutors to give comprehensions of the Process Approach by providing a definition of it and describing various stages involved in it. In the first place, they defined the Process Approach as:

“...Process Approach may mean the teaching of writing will be focused on the real writing ability of a student and you know cultivate his genuine appreciation for English literature." (teacher $A$ )

“... it stresses the writing process, how to inspire students, how to gather information, how to organize the ideas, how to negotiate with yourself or peers, how to revise and so on." (teacher $C$ )

Teachers' own definitions varied. Teachers placed a distinct emphasis on the Process Approach. For instance, teacher A defined it as focusing on the "real writing ability of a student". In contrast, teacher B explained it from the cognitive perspective. In addition, teacher $\mathrm{C}$ gave an explanation that focused on "the writing process" which includes "how to gather information, how to organize the ideas, how to revise" etc. Although teacher D did not define it, she described every stage in detail.

In the second place, they described each writing stage of the process based on their understanding. Teacher A and C simply mentioned each stage without explicit words.

"...I guess brainstorming, discussing, negotiating, debating and revising should be the major ones." (teacher C)

By contrast, teacher B and D provided detailed description for each stage in the process writing.

“... First step is the birth of ideas... Second step is students organize ideas... third step is students write the first draft. Forth step is their first drafts are grouped, five copies are singled out and sample-evaluated in class by the instructor, while the rest are distributed among the students, who are responsible for improving and revising the writing they are given. Fifth step is drafts are returned and improvements are made based upon peer feedback. And the final step is five copies best done are displayed..." (teacher B) 
"First... have a brain-storm of the topic. Second... write down the useful expressions. Third... write the composition. Fourth, I will collect all the composition and analyze the problems in students composition. Fifth...point out the problems and give some suggestions. Next... refine their composition. Then... one or two good sample from student' works and analyze... Finally, I ask students have a reflection about their own writing and grade it by themselves." (teacher $D$ )

From the two teachers' detailed description about each step involving in the Process Approach, it can be analyzed that they shared key similarities while holding different views. For the similarity, the main steps were consistent such as the brainstorm, drafting, feedback, and revision. Regarding the differences teacher B used peer feedback for evaluation while teacher D applied teacher feedback to provide suggestions for students' drafts. In the final stage, teacher B only exhibited the best five copies, by contrast, teacher D not only displayed and analyzed good students' samples but also required learners to demonstrate further consideration about their own writing.

\subsection{Research Question 3: To What Extent Do Teachers Apply and Students Experience the Process Approach?}

In terms of how students experienced the process writing strategy, Questions 5 to 7, and 9 to 14 in the student questionnaire (see Appendix A) were on closer investigation about various particular aspects of the process writing.

Figure 3 shows the degree of importance of each stage in the students' eyes. The chart indicates that the prewriting stage was considered as the most important part with an average rate of 6.3 followed by the editing and evaluation stage rated as 5.5 and 5.3 respectively. Drafting and rewriting the draft were seen as the least important stages.

Table 2 depicts that $66 \%$ of the respondents preferred B: text-specific comments in detail, followed by vocabulary suggestion (18\%), grammatical error correction (8\%), and style suggestions (6\%). One respondent commented "creative comments on the views or thinking". It showed that detailed suggestions related to students' written pieces' were favored by most of the respondents.

Table 3 indicates that 32 respondents revised the writing carefully based on

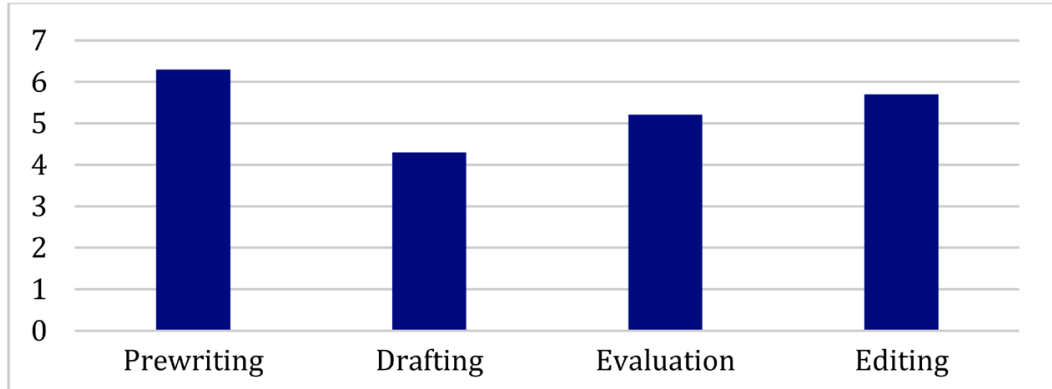

Figure 3. Rating the importance of each stage in the Process Approach on a scale from 1 to 7,7 being very important. 
teacher feedback, covering 64\%. 12 respondents stated that they did not modify the draft, although they might read feedback carefully, 3 students chose to have a look at the final grade without revision, and 1 student even paid no attention to it. It can be seen that $32 \%(n=16)$ of the respondents did not further correct their drafts after getting the feedback.

Question 13 in the student questionnaire (see Appendix A): Do you think it is important to consider the readers when you are writing? $94 \%$ of the respondents ( $\mathrm{n}=47$ ) thought it was significant to achieve a sense of audiences. In contrast, only 3 respondents paid no attention to the audiences.

This was a multiple choice question that permitted to select more than one answer. The result was illustrated in Table 4. It can be seen that item 2: when writing is graded and item 3: writing with social purpose, were selected by most respondents $(74 \%, 64 \%)$, and followed by item 1: in exams, 24 respondents chose it. Obviously, only one student never considered the target audience.

In addition, teachers' comments towards whether they applied the Process

Table 2. What kind of feedback do you like? $(\mathrm{n}=50)$.

\begin{tabular}{lcc}
\hline \multicolumn{1}{c}{ Statements } & Number & Percent \\
\hline $\begin{array}{l}\text { A. Grammatical errors correction suggestions } \\
\begin{array}{l}\text { B. Text-specific comments in detail (ideas not clearly enough, lack of } \\
\text { critical thinking) }\end{array}\end{array}$ & $33 \%$ \\
$\begin{array}{l}\text { C. Vocabulary suggestions (e.g. suggesting a better word to replace the } \\
\text { original one) }\end{array}$ & 9 & $66 \%$ \\
$\begin{array}{l}\text { D. Styles suggestions (e.g. whether it is formal or not) } \\
\text { Others please specify }\end{array}$ & 3 & $18 \%$ \\
\hline
\end{tabular}

Table 3. Students' responses to feedback $(n=50)$.

\begin{tabular}{ccc} 
Statements & Number & Percent \\
\hline Just check out the score without any further correction & 3 & $6 \%$ \\
Read it carefully but without any changes to the writing & 12 & $24 \%$ \\
Revise the writing carefully according to teacher's comments & 32 & $64 \%$ \\
Never pays attention to it & 1 & $2 \%$ \\
Others please specify & 2 & $4 \%$ \\
\hline
\end{tabular}

Table 4. On which occasion would you consider the target audience?

\begin{tabular}{ccc}
\hline Statements & Number & Percent \\
\hline In exams & 24 & $48 \%$ \\
When the writing is graded (e.g. homework) & 32 & $64 \%$ \\
Writing with social purposes (e.g. writing an application letter, emails) & 37 & $74 \%$ \\
Never considered & 1 & $2 \%$ \\
Others please specify & 1 & $2 \%$ \\
\hline
\end{tabular}


Approach into writing instruction and how it operated would be presented and analyzed as following. In the interview, teacher A and B mentioned that they have used the process writing in class. When asking question 4: did you wholly or partly use the Process Approach, could you say a few particular features of your Process Approach and is it practical or useful in current writing instruction? They expressed their ideas as following:

"It's useful but partly used, because they have to pass many exams and don't have enough class time. The feature of my teaching is that I always ask them to exchange their works for correction." (teacher $A$ )

"I partly used it due to class time limited. It's very useful... because of the collaborative work and the respect for individualized planning modes... When students finished their first drafts, I will provide model texts for comparison... I also like to incorporate the exchanging of drafts, so that the students become the readers" (teacher $B$ )

To be analyzed, teacher A and B both partly used the Process Approach and thought it was useful. They considered the collaborative work as an important feature in process writing class. In contrast, answers from teacher $\mathrm{C}$ and $\mathrm{D}$ were like this:

"I never tried it, because the demanding teaching schedule doesn't allow me to spend the class time on writing." (teacher $C$ )

"I didn't use it. As time is limited, and students have a lot of homework to do, I don't think it's quite practical for it lasts for a long time and students may find it's very boring to talk about the same thing again and again." (teacher D)

Teacher C and D seldom applied the Process Approach as they thought it was not practical due to limited class time.

\subsection{Research Question 4: What Do Teachers and Students Think of the Product Process Approach?}

In the last part of the survey, the aim was to find out Chinese English teachers' and majors' attitudes towards the synthesis methodology: the Product Process Approach.

Table 5 shows the result that 30 respondents were in favor of the Product Process Approach covering 60\%, followed by 14 respondents (28\%) who preferred the process-oriented class and only 6 respondents who chose the product-based method. In addition, all of the respondents were asked to briefly explain why they selected it. Among the 6 who preferred the Product Approach, half of them held the opinion that the product-oriented method helped them to

Table 5. Which teaching method do you prefer?

\begin{tabular}{ccc}
\hline Methods & Number $(\mathrm{n}=50)$ & Percent \\
\hline The Product Approach & 6 & $12 \%$ \\
The Process Approach & 14 & $28 \%$ \\
The Product Process Approach & 30 & $60 \%$ \\
\hline
\end{tabular}


pass the exam.

Noticeably, the majority of the respondents (60\%) supported the Product Process Approach. Nearly half of them $(n=14)$ took the same point of view that the Product Process Approach "combines the advantages of both approaches" which was considered to be a "feasible", "efficient", "interesting", "comprehensive", and "useful" method. One of them noted different roles of the two approaches that "the former approach is the foundation of good writing, and the latter one is for the better writing". Furthermore, one pointed out that "both help me survive the exam and complete creative writing". In addition, one mentioned, "it provides not only the model of writing but also the chances to carefully examine one's writing".

After presenting student participants' views towards three writing approaches, here, teachers' attitudes toward the possibility to combine the Product Approach and the Process Approach would be illustrated. Teachers' opinions varied. Three of the teachers thought it was possible while one (teacher D) answered that it was "challenging" to combine the two approaches in a real class. Teacher A noted that "they are not in conflict", which echoed with teacher C's opinion that the two approaches complement each other: "on one hand, students get sufficient ideas, inspiration, resources and support, namely, they know clearly what to put down; on the other hand, they may achieve a sense of achievement at the sight of their finished work" (teacher C). Teacher B believed that the combination depends on the genres because "certain genres lend themselves more favorably to one approach more than the other". While he agreed it was possible to integrate the practice of studying written models into the process writing, he pointed out that the two approaches weigh differently when teaching different genres.

\section{Discussion}

By analyzing the collected data and reflecting on the literature review in the previous parts, this chapter tries to discuss how and to what extent the four research questions are answered, namely what are the teachers and students' perception of the two approaches and how do they think of the combination of the two in practice. In light of the discussion, the existing problems and obstacles in teaching and learning English could be better understood and further examined. Potential difficulties could hopefully be anticipated.

\subsection{Research Question 1: What Do You Think of the Product Approach?}

In the questionnaire, the results revealed students' global understanding of the Product Approach. However, although they considered both sides of the teaching method, while many of them are aware of its advantages in exam-oriented teaching and its drawback in creative learning, their knowledge of the setbacks of the Product Approach remain limited. Compared with the number of stu- 
dents choosing the positive descriptions of the Product Approach (imitation of writing models are useful; it helps pass the exam), much fewer students agreed with the idea that the Product Approach's lack of the concept of process and audience (only $24 \%$ and $22 \%$ of the respondents selected the negative aspects B and $\mathrm{D}$ respectively). There could be two explanations of their disagreement. The first possible reason is that the English majors disagreed because they really did not think the Product Approach lacks the concept of process and audience. Another possible explanation would be that they were not quite aware of these problems of the Product Approach. As mentioned in the literature review, the Product Approach leads students to the view that writing is a product to be evaluated and at times students would regard the first draft as the final piece without revision (Watson, 1982; Badger \& White, 2000). Here, students were just not or only partially aware of the problems.

The teachers' perception of the Product Approach appeared to be more comprehensive. On one hand, they affirmed the advantages of the Product Approach that students were able to learn useful writing techniques especially those that are relevant to exam and assessment by exposing students to given writing models. In addition, Muncie (2002) suggested that there was a need for grammatical instruction for EFL learners in writing class. The students' positive attitudes towards writing models investigated in Figure 2 echoed with the teachers' perception, which could also be supported by Krashen's input theory (1985). On the other hand, however, teachers seemed keener to describe the shortcoming of the Product Approach. They generally agreed that the Product Approach attaches little importance to the process of writing. Comments were made that the Product Approach leads students directly to the final piece regardless of the stages such as brainstorming, drafting, and revision etc. This results in the vague concept of audience and purpose, little attention to feedback and no experience of the writing process. Additionally, teachers $\mathrm{B}, \mathrm{C}$, and $\mathrm{D}$ all mentioned the rigidity of the Product Approach. The fixed way of imitation renders students' work similar with one another and means it lacks personality. As teacher $\mathrm{C}$ pointed out, without guidance through the process, students have no idea what to put down but to echo with what they have remembered by imitation.

\subsection{Research Question 2 and 3: To What Extent Do Students and Teachers Understand the Process Approach? To What Extent Do Teachers Apply and Students Experience the Process Approach?}

\subsubsection{Teacher Factor}

Teachers gave different definitions of the Process Approach, which might be influenced by their individualized teaching experience and styles. For example, teacher B emphasized the "cognitive strength" while teacher A was more interested in students' "writing ability". In L1, the Process Approach could be generalized into these sub processes, namely prewriting, drafting, revising and editing (Tribble, 1996; Williams, 2005). 
However, these four teachers' definitions showed that they might lack comprehensive knowledge of the Process Approach. Teacher D, for instance, could not provide a definition of the Process Approach though she thought it was effective. Caudery (1995) carried out an online survey of L2 writing teachers various concepts of the Process Approach. It suggested two trends: diversification (individualized the teaching approach) and simplification (adapting the original L1 process-oriented method to the L2 education environment), which may result in teachers' different definitions of the Process Approach as indicated in the four teachers' answers.

White and Arndt (1991) describe every stage involved in the process writing in detail. Teacher A thought the prewriting stage meant providing "the basic and native sentence structure and expression", while teachers B, C, and D labeled "brainstorming" as the prewriting activity. Moreover, there was one inspiring factor that both teacher B and D pointed out there should be a stage of "choosing and giving good written examples" from students for further understanding of "how to construct good written pieces" after the traditional final stage of editing. It argued here that the two Chinese teachers might consider the writing process as a circle; the final stage appreciation of the good written examples could accumulate experience and pave the road for the next writing task.

On one hand, all the four teachers held positive attitudes towards the Process Approach as they thought it was useful to some degree. They agreed that students could benefit from the process writing instruction. Various pioneering studies about the process writing (Raimes, 1987; Cumming, 1989) used asmall-scale case study method and considered the recursively and non-linear process-oriented strategy to some degree might improve student's writing ability and problem-solving skill. A quantitative and qualitative study of the $1992 \mathrm{Na}-$ tional Assessment of Educational Progress in the US found that students with the process guidance (e.g. prewriting instruction) moderately outperform those without (Goldstein \& Carr, 1996). It seems that when teachers applied the Process Approach, to some extent, students might benefits from this teaching method.

On the other hand, only teachers A and B partly applied the Process Approach into their writing instructions. Teachers $\mathrm{C}$ and $\mathrm{D}$ did not use it and thought it was unpractical due to "limited class time" and "demanding teaching schedules". It argues that teachers A and B used elements of the process writing, however they emphasized differing angles of the writing instruction and created distinct class style and learning atmosphere. Teacher A may focus on mutual corrections among students and require them to "find good and bad sentences" which tended to be perceived as local language learning level. Whereas, teacher B was interested in both the "individualized planning mode" as well as "collaborative work" referring to "exchanging drafts" in class to create an awareness of writer and reader. Teacher B's writing class seemed to establish a kind of collaborative circumstance and atmosphere (Vygotsky's social constructivism theory, 1987) by 
involving students into a virtual community to communicate their writing purposes and expressed their ideas. Zamel (1987) noted that supportive and comfortable class atmosphere was perceived as important to encourage learners in a collaborative learning mode recognizing the relationship between the writer and reader.

\subsubsection{Student Factor}

Firstly, from the student's questionnaire, although 14 respondents claimed they did not know or were not sure about the Process Approach, all of the 50 respondents composed their dissertations by wholly or partly using the process writing strategies. It is argued here that English majors might not have a clear picture about what the Process Approach was even though they had experiences in process writing. Secondly, although learners might not be fully aware of the process writing concept, they had personal attitudes toward each stage involved in process writing (as shown in Figure 3). In line with learners' perceptions, prewriting and editing played significant roles, and they regarded drafting procedure as the least important part. In a traditional Chinese college English writing instruction mode, teachers assign the writing tasks as homework and usually students hand in the written work without being provided any feedback until the mark is given. The lack of guidance in the middle of writing process would lead the first draft directly to the final product without any modification (Liu, 1999; $\mathrm{Wu}, 2010)$. By contrast, the prewriting stage makes up a considerable part in writing class. Usually, the teacher would first give a topic and background information and ask students to discuss in group or with the whole class. Teacher would guide the process and introduce to students useful insights as well as native writing patterns. Students would then be asked to do the outlining or directly start to write. Chinese English majors could be influenced by such a traditional teaching method so that their attitudes towards drafting were not as positive as that of prewriting as shown from the results of the questionnaire.

Thirdly, for the feedback part, Zamel (1987),

"viewing texts as products to be judged and evaluated... thus, the changes and revisions that students incorporate not only fail to clarify what they intended to communicate but may have little to do with what was originally intended." (p. 81)

Thus, it suggested that teachers needed to regard writing as a process which took a period of time rather than judging the first draft as the final one (Zamel, 1987). Data (shown in Table 3) revealed that $64 \%$ of respondents would revise the writing carefully according to their teachers' comments. It seemed that teacher feedback influences learners' following revision procedure (Ferris, 1997). $66 \%$ of the total respondents preferred detailed suggestions related to their texts (as shown in Table 2) followed by a choice of vocabulary suggestions and grammatical error correction suggestions. Thus, comments related to learners' specific texts in detail, overall suggestions on the whole passage structures, and several grammatical and vocabulary errors may be useful for students' effective 
revision part.

Fourthly, various scholars (Tribble, 1996; Hedge, 2005) noted that before publication it would be better to achieve a sense of audience as well as the writing purpose, hence it may improve effective communication between writer and reader. Since English majors are required to achieve a higher writing level of communication than a mere linguistic skill, Diaz suggested that process-oriented class modes might help and encourage students to regard themselves as real writers and appreciate their written products as meaningful pieces (as cited in Zamel, 1987) rather than merely reflection of the learned sentence patterns or grammar knowledge. In the questionnaire, $94 \%$ of the respondents thought it was significant to consider target readers. It could be argued that English majors have already built awareness in meeting readers' expectations before and during writing. This phenomenon might be different from other Chinese scholars' study $(\mathrm{Wu}, 2010)$ where they mentioned college learners lacked the concept of audience and writing purpose. The findings in this study could be seen that English majors might make a progress in building concept of target audiences.

\subsection{Research Question 4: What Do Teachers and Students Think of the Product Process Approach? Is It Practical in Current Writing Instruction?}

Collected data revealed that 30 respondents held positive attitudes toward the Product Process Approach, representing 60\% (as shown in Table 5). Half of the student participants explained the similar reason that the Product Process Approach "combines the advantages of both approaches". In line with teachers' attitudes, three of the teachers thought it was possible to combine the Product Approach and the Process Approach, while one (teacher D) answered that it was "challenging" in real class.

A pioneering study by Watson (1982) suggested that models were an important input, however merely imitating the provided sentence structures may cause the trouble that "the student product... is likely to be very superficial: a collection of sentences rather than a text" (p. 6). As teacher C commented "the students' writings look similar and seldom can we find a distinguished one that can reflect the students' own thinking or personality". Hence, it seemed that in ESL and EFL writing class, "models should be introduced and utilized" not for students' merely copying and imitating but for "both prewriting discussion and post-writing critique, for both analysis of the model and evaluation of students' own productions" (Watson, 1982: p. 12). In addition, Watson argued that "models can be most useful when fully integrated into the sequence of activities within the writing lesson". It is argued that incorporating the Product Approach within the process-oriented strategies could bring benefits, for example, it may enhance learners' language knowledge because of exposure to rhetoric features and sentences structures, develop their communicative abilities thanks to translation of the their own opinions and reinforce students' skills by involving a range of writing activities such as drafting, revising and editing. Another significant study 
by Flower and Hayes (1981) pointed out a cognitive process theory of writing containing three factors "the task environment, the writer's long-term memory, and the writing process" (p. 369). The long-term memory referred as a writer's repertoire of resources and knowledge which could be subdivided into lexical items, rhetorical devices, sentence patterns to global writing plans and background information of the topic. Students' repertoire may mainly store from learning and memorizing the text-books and given written models. Flower and Hayes thought that composing procedure was the thinking process with various writing goals to set and achieve. Then writers interpreted and wrote down their ideas into paper in order to communicate their opinions with potential readers. It could be seen that a writer with a long-term memory and goal-directed writing process might guide and help one's writing. Furthermore, Kamimura (2000) carried out an investigation by involving 35 Japanese EFL college students into a study: whether it was needed to either combine the product-based approach and process-oriented approach or use only one approach was adequate to cultivate skilled writers. The result argued and suggested that if L2 writing instruction combined the product-oriented method and process writing strategies, non-native learners may take advantage of it.

In addition, a study in one Chinese university by $\mathrm{Wu}$ (2010), suggested that writing instruction could apply the Product Approach with the Process Approach together in accordance to particular writing tasks and writing genres. Chen (2005) carried out a study by involving 60 college students into an experiment on the effectiveness of the traditional product-based method and the Process Approach. The test result showed that the product method was much more appropriate for unskilful learners while the process method was suitable for students with high-level language proficiency. It argued that both approaches have merits and demerits, and a combination of them or only used one approach was in accordance with learners' English proficiency. As teacher B in the interview also commented "depending on the students, and the genre of the text... formal letters would be perhaps more suited to a product-driven approach... discursive essays may lend themselves to process-driven approaches".

\section{Conclusion}

\subsection{Main Findings}

The main objective of this study was to investigate Chinese English teachers and majors' perceptions of the Product Approach and the Process Approach and their attitudes toward the combination of the two. 50 English majors and 4 English teachers from China took part in the research. Through questionnaires to the students and interviews to the teachers, useful information was provided. By analyzing the collected data, the perceptions of the two approaches and attitudes toward the synthesis could be realized.

Firstly, in terms of the Product Approach, most of the participants thought it was useful as it provided writing models and adequate language input. It was 
agreed that the Product Approach helped students to survive exams by practicing particular sentence structures before tests. However, the participants thought that the product-oriented class mode might ignore the students' creative thinking, lack the concept of the writing purpose and audience and overlook the need for revision.

Secondly, in terms of the Process Approach, the four teachers interviewed thought the Process Approach could be useful in enhancing students' writing skill. Among the teachers who used the Process Approach it could be seen that they did not apply the whole writing process as the White and Arndt Diagram explicitly and clearly described (1991). This could be because the Process Approach was originated in L1 and might not be wholly suitable for the EFL context. Thus, the simplification and adaptability (Caudery, 1995; Leki, 2001; Muncie, 2002) of the Process Approach into Chinese English writing instruction was considered to be important. In addition, according to the students' data, it revealed that most of the participants knew the concept of the Process Approach and had experiences of process writing. Although the student participants might not have a clear picture of each stage involved in the process, they showed more attention to the prewriting and editing parts and less to drafting.

Thirdly, with regard to the attitudes toward the synthesis: the Product Process Approach in China English major writing course, the majority of the students and the four teachers held positive views on the combination. For the students, they pointed out that the synthesis could not only provide them with language input but also help them be creative and active in the writing process. For the teachers, three of them agreed that the synthesis may help improve the English writing teaching and learning. On one hand, students as EFL learners could obtain opportunities to acquire grammar knowledge, and good sentence structures; on the other hand, different from only imitating and copying the models learners were involved in creating their own ideas and developing problem-solving skills through the writing process.

\subsection{Limitations and Pedagogical Implications of the Study}

\subsubsection{Limitations}

After discussing the main findings, various limitations of this study also need to be addressed. In the first place, with regard to the research methods, two problems need to be mentioned. First is the lack of long-term empirical research which could bring much more valid and reliable data to examine the effectiveness of the Product Process Approach. Thus, there needs more research in this topic. As a teacher in the near future, further research needs to be carried out on the feasibility and practicality of this synthesis: the Product Process Approach to overcome this constraint. Secondly, in terms of the student questionnaire, a follow-up interview could not be carried out for detailed and further information. In the second place, although 50 students and 4 teachers were involved into this research and certain amount of the firsthand information from the participants was obtained, it is a rather small-scale study which could not convincingly 
represent the whole view of the Chinese university teachers and students. The conclusion of this paper would be more applicable to small-size (about 25 students) lower-intermediate English class in vocational colleges in China.

\subsubsection{Pedagogical Implications}

From what has been discussed and concluded above, it is argued that while the Product Approach seems still necessary for writing in Chinese English majors' class the focus on writing teaching and learning needs to be shifted from the final product to the writing process. More effort needs to be made at each stage of writing such as prewriting and revision and more attention needs to be paid to the students' role in class so that writing might be seen as communicative experience instead of a merely linguistic outcome. In the EFL context however, a complete copy of the L1 Process Approach does not seem feasible because of different local needs and education systems. Simplification and adaptability should be taken into consideration when applying the Process Approach. A possible solution might be the combination of the Product Approach and the Process Approach. Previous studies and teachers' interview in this research study implied that the two approaches could work together (Watson, 1982; Kamimura, 2000; Chen, 2005) if properly balanced in accordance with different learners and genres.

\section{Acknowledgements}

Research on the effectiveness of the writing approaches in the vocational English writing classes. Project director: Hu Zhenzhen (School of Foreign Languages). Project number: 2018cdfzjj04.

\section{Conflicts of Interest}

The authors declare no conflicts of interest regarding the publication of this paper.

\section{References}

Badger, R., \& White, G. (2000). A Process Genre Approach to Teaching Writing. ELT Journal, 54, 153-160. https://doi.org/10.1093/elt/54.2.153

Bell, J. (2005). Doing Your Research Project: A Guide for First-Time Researchers in Education, Health and Social Science (4th ed.). Berkshire: Open University Press.

Brown, H. D. (1994). Teaching by Principles: An Interactive Approach to Language. Columbia: Columbia University Teacher's College.

Caudery, T. (1995). What the "Process Approach" Means to Practicing Teachers of Second Language Writing Skills. The Electronic Journal for English as a Second Language, 1, 1-12.

Chen, M. (2005). Mutual Effects of the Writing Instruction Mode and Students' Writing Abilities. Foreign Language Teaching and Research, 37, 460-464.

Cohen, L., Manion, L., \& Morrson, K. (2007). Research Methods in Education (6th ed.). London: Routledge. https://doi.org/10.4324/9780203029053

Cumming, A. H. (1989). Writing Expertise and Second-Language Proficiency. Language 
Learning, 39, 81-141. https://doi.org/10.1111/j.1467-1770.1989.tb00592.x

Ferris, D. R. (1997). The Influence of Teacher Commentary on Student Revision. TESOL Quarterly, 31, 315-339. https://doi.org/10.2307/3588049

Flower, L., \& Hayes, J. R. (1981). A Cognitive Process Theory of Writing. College Composition and Communication, 32, 365-387. https://doi.org/10.2307/356600

Goldstein, A. A., \& Carr, P. G. (1996). Can Students Benefit from Process Writing? NAEP Facts, 1, 2-7.

Harmer, J. (2007). How to Teach English. Harlow: Pearson Longman.

Hedge, T. (2005). Writing (2nd ed.). Oxford: Oxford University Press.

Kamimura, T. (2000). Integration of Product and Process Orientations in EFL Writing Instruction. RELC Journal, 31, 1-28. https://doi.org/10.1177/003368820003100201

Krashen, S. D. (1985). The Input Hypothesis: Issues and Implications. London: Longman.

Leki, I. (2001). Materials, Educational, and Ideological Challenges of Teaching EFL Writing at the Turn of the Century. International Journal of English Studies, 9, 197-209.

Liu, R. (1999). Lun Daxue Yingyu Jiaoyu. Beijing: Foreign Language Teaching and Research Press.

Luo, Y., \& Li, H. (2003). Jieguofa zhende guoshi lema? Yingyu xiezuo jiaoxue "jieguofa” yu "guochengfa" de bijiaoyanjiu [Is Product Approach Outdated?-A Comparative Study on the Product and Process Approach in EFL College English Context in China]. Journal of Xi an Foreign Languages University, 11, 22-25.

Miao, Y., Badger, R., \& Zhen, Y. (2006). A Comparative Study of Peer and Teacher Feedback in a Chinese EFL Writing Class. Journal of Second Language Writing, 15, 179-200. https://doi.org/10.1016/j.jslw.2006.09.004

Muncie, J. (2002). Finding a Place for Grammar in EFL Composition Classes. ELT Journal, 56, 180-186. https://doi.org/10.1093/elt/56.2.180

Munn, P., \& Drever, E. (2004). Using Questionnaires in Small-Scale Research: A Beginner's Guide. Glasgow: Scottish Council for Research in Education.

Nunan, D. (2001). Second Language Teaching and Learning. Beijing: Foreign Language Teaching and Research Press.

Pincas, A. (1982). Writing in English. London: Macmillan.

Raimes, A. (1987). Language Proficiency, Writing Ability, and Composing Strategies: A Study of ESL College Student Writers. Language Learning, 37, 439-468. https://doi.org/10.1111/j.1467-1770.1987.tb00579.x

Rao, Z. (2007). Training in Brainstorming and Developing Writing Skills. ELT Journal, 61, 100-106. https://doi.org/10.1093/elt/ccm002

Scrivener, J. (2005). Learning Teaching: A Guidebook for English Language Teachers. Oxford: Macmillan.

Stringer, E. T. (2014). Action Research: A Handbook for Practitioners (4th ed.). Thousand Oaks, CA: SAGE.

Susser, B. (1994). Process Approaches in ESL/EFL Writing Instruction. Journal of Second Language Writing, 3, 31-47. https://doi.org/10.1016/1060-3743(94)90004-3

Tribble, C. (1996). Writing. Oxford: Oxford University Press.

Vygotsky, L. S. (1987). Mind in Society: The Development of Higher Psychological Processes. Cambridge, MA: London Harvard University Press.

Watson, C. B. (1982). The Use and Abuse of Models in the ESL Writing Class. TESOL Quarterly, 16, 5-14. https://doi.org/10.2307/3586558 
White, R., \& Arndt, V. (1991). Process Writing. Harlow, UK: Longman.

Williams, J. (2005). Teaching Writing in Second and Foreign Language Classrooms. New York: McGraw Hill.

Winer, L. (1992). "Spinach to Chocolate": Changing Awareness and Attitudes in ESL Writing Teachers. TESOL Quarterly, 26, 57-80. https://doi.org/10.2307/3587369

Wu, T. (2010). Study of "the Product Approach" and "the Process Approach" in Writing Class for University Students. Second International Workshop on Education Technology and Computer Science, 6, 623-626.

Yang, L., \& Gao, S. (2013). Beliefs and Practices of Chinese University Teachers in EFL Writing Instruction. Language, Culture and Curriculum, 26, 128-145. https://doi.org/10.1080/07908318.2013.794817

You, X. (2004). New Directions in EFL Writing: A Report from China. Journal of Second Language Writing, 13, 253-256. https://doi.org/10.1016/j.jslw.2004.09.002

Yu, S., \& Lee, I. (2015). Understanding EFL Students' Participation in Group Peer Feedback of L2 Writing: A Case Study from an Activity Theory Perspective. Language Teaching Research, 19, 572-593. https://doi.org/10.1177/1362168814541714

Zamel, V. (1987). Recent Research on Writing Pedagogy. TESOL Quarterly, 21, 697-715. https://doi.org/10.2307/3586990 


\section{Appendices}

\section{Appendix A: Questionnaire for Students}

1. What is your education degree?

- College degree

- Postgraduate

- Undergraduate

2. What are the main difficulties of English writing to you (you can choose more than one answer):

- Lack of confidence

- Lack of grammatical knowledge

- Lack of vocabulary

- Lack of enough writing practice

- Lack of proper guidance

- Not familiar with English writing conventions

- Not familiar with different formats of genres

- Others, please specify

3. What do you think of the traditional Product Approach (students imitate the writing models provided by teachers or text books) in English writing class? [Multi-choice]

- It is helpful to provide writing models for students to imitate.

- It only focuses on the final piece without revisions.

- It helps to learn various good sentence patterns.

- It lacks the concept of audience.

- It helps to survive the exam.

- It lacks creative thinking.

- Others, please specify.

4. Do you know the Process Approach (a writing process including prewriting, drafting, revising, and editing)?

- Yes, I know it.

- Not sure about it.

- No, I don't know it.

5. Have you ever experienced the Process Approach when you are writing in English?

- Yes

- No

- Not sure

6. Rating the importance of each stage in the Process Approach on a scale from 1 to 7,7 being very important. 
- Prewriting stage (e.g. brainstorming, planning)

- Drafting

- Evaluation (e.g. receiving teacher feedback)

- Rewriting the draft

- Editing

7. Do you think it is useful to undertake some pre-writing activities (e.g. brainstorming, outlining, questioning and answering, making notes)?

- Strongly agree

- Agree

- Neither agree nor disagree

- Disagree

- Strongly disagree. Please tell me the reason.

8. Do you think writing models (e.g. text books, models provided by teachers) are useful?

- Strongly agree

- Agree

- Neither agree nor disagree

- Disagree

- Strongly disagree

9. What kind of feedback do you like? (Thinking one)

- Grammatical errors correction suggestions. Text-specific comments in detail (ideas not clearly enough, lack of critical).

- Vocabulary suggestions (e.g. suggesting a better word to replace the original.

- Styles suggestions (e.g. whether it is formal or not).

- Others. Please specify.

10. What is your response to feedback (e.g. teacher feedback, peer feedback) on your English writings?

- Just check out the score without any further correction.

- Read it carefully but without any changes to the writing.

- Revise the writing carefully according to teachers' comments.

- Never pays attention to it.

- Others please specify.

11. Which of the following stages did you use when writing your paper? [Multi-choice]

- Planning (e.g. finding background information and discussing with your tutor)

- Drafting

- Getting the first feedback

- Rewriting the draft

- Getting further feedback

- Rewriting again 
- Proofreading

- Editing

- Others, please specify

12. Before you hand in your final piece, usually how many times do you revise your work?

- One

- Two

- More than two

- Never

13. Do you think it is important to consider the readers when you are writing?

- Yes

- I don't care

- No

14. On which occasion or occasions would you consider meeting the expectations of the target reader (e.g. your supervisor, teachers, classmates, a social community etc.)?

- In exams

- When the writing is graded (e.g. homework)

- Writing with social purposes (e.g. writing an application letter, emails)

- Never considered

- Others please specify

15. Which teaching mode of writing do you prefer? Please write down the main reasons briefly.

- The Product Approach (e.g. teachers provide writing models and students imitate them to fulfill a writing task)

- The Process Approach (e.g. a writing process which may include planning, drafting, revising and editing)

- The Product Process Approach (e.g. combining imitative and creative writing in a writing process)

\section{Appendix B: The Schedule of Interview}

\section{Interview schedule:}

First: introduction. I would ask you a few questions about your perceptions of the Process Approach and attitudes towards the Product Process Approach implementation into EFL writing instruction. I am very grateful if you could answer these open-ended questions regarding your teaching experience in EFL writing. During the interview, our conversations will be recorded by the computer and I promise your answers will be kept confidential. Your answers are very important for my study and will be stored in my personal computer and 
only be used for this research study. Thank you very much for your time.

Second: questions

1) How many years have you been teaching English writing class?

2) What do you think of the traditional Product Approach in writing class? (e.g. advantages and disadvantages)

3) As the Process Approach may mean different things to different instructors in different contexts (e.g. L1, L2, EFL writing), what do you understand by the concept of the Process Approach? (e.g. your definition of it, descriptions of different writing stages such as prewriting or revision)

4) Do you use the Process Approach in EFL writing class? If yes, how do you use it in your class (e.g. do you wholly or partly use these stages such as planning, drafting etc. and could you tell me some particular features of your process approach to teaching EFL writing)? Is it practical or useful in current writing instruction? If your answer is no could you tell me the reason?

5) Do you think it is possible to combine the Product Approach and the Process Approach in current writing instruction? (E.g. is there a certain degree of integration of these two approaches? If yes, how it operates? If no, what are the possible challenges?)

Third: thank you for teachers' cooperation and insightful answers.

\section{Appendix C}

\section{A Transcript of the teacher interview (Teacher B)}

B (teacher B) I (interviewer)

I: I would ask you a few questions about your perceptions of the Process Approach and attitudes towards the Product Process Approach implementation into EFL writing instruction. I am very grateful if you could answer these open-ended questions regarding your teaching experience in EFL writing. During the interview, our conversations will be recorded by the computer and I promise your answers will be kept confidential. Your answers are very important for my study and will be stored in my personal computer and only be used for this research study. Thank you very much for your time.

B: Ok, I will be happy to answer your questions.

I: Thank you. Now let's begin with the first question.

B: Sure. Go ahead.

I: How many years have you been teaching English writing class?

B: 12 years.

I: En... What do you think of the traditional Product Approach in writing class, For example, the positive and negative aspects of the Product Approach? B: Let me think... The advantages... first of all it is helpful to provide model writings for students to imitate. En... secondly it helps to learn various good sentence patterns. And it helps to survive the exam. The disadvantages, it only focuses on the final product, and sometimes lacks the concept or ideas of the audience and students cannot develop creative thinking. 
I: Next question, the Process Approach may mean different things to different instructors in different contexts, what do you understand by the concept of the Process Approach? Could you please firstly give a definition of it, and secondly describe every writing stage such as prewriting or revision in detail?

B: ...in most part of my teaching, the Process Approach is employed as an effective tool to build up EFL learners' cognitive strength,...which means the realization of their English input and output parts.. .the Process Approach is much favored because it indeed enhances the quality of the final product. And... First step is the birth of ideas... Second step is students organize ideas... third step is students write the first draft in class with time limits. Forth step is their first drafts are grouped, five copies are singled out and sample-evaluated in class by the instructor; while the rest are distributed among the students, who are responsible for improving and revising the writing they are given. Fifth step is drafts are returned and improvements are made based upon peer feedback. And the final step is five copies best done are displayed...

I: Thank you for your answer. Next question is do you use the Process Approach in EFL writing class?

B: Yes.

I: If yes, how do you use it in your class? Do you wholly or partly use these stages such as planning, drafting and could you tell me some particular features of your process approach? Is it practical or useful in current writing instruction?

B: Yes, I partly used it due to class time limited. Well, it is very useful...important because of the collaborative work and the respect for individualized planning modes... When students finished their first drafts, I will provide model texts for comparison... I also like to incorporate the exchanging of drafts, so that the students become the readers of each other's work...

I: Ok, the last question is do you think it is possible to combine the Product Approach and the Process Approach in current writing instruction?

B: En... Yes, possible. I: If yes, in your opinion, how it operates?

B: I think the two approaches are not necessarily incompatible. And I believe that process writing can be integrated with the practice of studying written models in the classroom. En... the approach that I decide to use will depend on the students, and the genre of the text. I mean, for example, formal letters, or postcards, the features are very fixed, would be perhaps more suited to a product-driven approach, it focuses on the format and grammar. Other genres, such as paper, may suit process-driven approach that focus on students' ideas.

I: That's all. Thank you for your time and cooperation. 